\title{
Atrazine reduces reproduction in fathead minnow (Pimephales promelas)
}

\author{
Donald E. Tillitt*, Diana M. Papoulias, Jeffrey J. Whyte ${ }^{1}$, Catherine A. Richter \\ Columbia Environmental Research Center, U.S. Geological Survey, 4200 New Haven Road, Columbia, MO 65201, USA
}

\section{A R T I C L E I N F O}

\section{Article history:}

Received 7 February 2010

Received in revised form 31 March 2010

Accepted 13 April 2010

\section{Keywords:}

Endocrine disruption

Atrazine

Reproduction

Gonad abnormalities

Fish

\begin{abstract}
A B S T R A C T
Atrazine, the widely used herbicide, has shown to affect the hypothalamus-pituitary-gonad axis in certain vertebrate species, but few studies have examined reproductive effects of this chemical on fish. Our study was designed to evaluate a population endpoint (egg production) in conjunction with histological (e.g., gonad development) and biochemical (e.g., hormone production) phenotypes associated with atrazine exposure in fathead minnows. Adult virgin breeding groups of 1 male and 2 females were exposed to nominal concentrations of $0,0.5,5.0$, and $50 \mu \mathrm{g} / \mathrm{L}$ of atrazine in a flow-through diluter for 14 or 30 days. Total egg production was lower (19-39\%) in all atrazine-exposed groups as compared to the controls. The decreases in cumulative egg production of atrazine treated fish were significant by 17-20 days of exposure. Reductions in egg production in atrazine treatment groups were most attributable to reduced numbers of spawning events with increased atrazine exposure concentrations. Gonad abnormalities were observed in both male and female fish of atrazine-exposed fish. Our results also indicate that atrazine reduces egg production through alteration of final maturation of oocytes. The reproductive effects observed in this study warrant further investigation and evaluation of the potential risks posed by atrazine, particularly feral populations of fish from streams in agricultural areas with high use of this herbicide.
\end{abstract}

Published by Elsevier B.V.

\section{Introduction}

Atrazine is one of the most commonly used herbicides in the world. In the United States this broadleaf herbicide is widely utilized on the majority of corn, sugarcane, and sorghum crops. Annual sales of atrazine in the US are approximately 33-36 million kilograms (Kiely et al., 2004). Moreover, atrazine has been routinely detected in surface and ground waters, particularly in mid-western states, at concentrations from 1 to $25 \mu \mathrm{g} / \mathrm{L}$ (Gilliom et al., 2006). Risk analysis of these concentrations of atrazine in surface waters of North America indicated the vulnerability of aquatic ecosystems through direct effects of atrazine on algae, phytoplankton, and macrophytes (Gidding et al., 2005). However, atrazine related effects through endocrine mechanisms on vertebrate reproduction and development have not received the same level of ecological risk evaluation.

Atrazine has neuroendocrine effects in vertebrates which lead to deregulation of ovarian function (Cooper et al., 2000). This

\footnotetext{
* Corresponding author at: Columbia Environmental Research Center, U.S. Geological Survey, Department of Interior, 4200 New Haven Road, Columbia, MO 65201, USA. Tel.: +1573876 1886; fax: +15738761896.

E-mail address: dtillitt@usgs.gov (D.E. Tillitt).

1 Present address: University of Missouri, Division of Animal Sciences, Columbia, MO 65211, USA.
}

reproductive dysfunction in mammals has been attributed to atrazine-induced effects on neurotransmitter and neuropeptide functions resulting in suppression of luteinizing hormone (LH) and prolactin surges with subsequent disruption of hypothalamic control of pituitary function (Cooper et al., 2007). The observed effects in mammals have occurred at elevated oral doses and it is not known if atrazine works through these same mechanisms of action in other vertebrates that are exposed through different routes of uptake. However, it is known that many of these same neuroendocrine pathways exist in fishes (Rosenfeld et al., 2007).

Atrazine caused reduced fry production in bluegill (Lepomis macrochirus) in mesocosm studies, but the reductions were attributed to secondary effects due to decreases in primary production caused by atrazine and reduced refugia for the developing fry (Kettle et al., 1987). Laboratory exposures of fathead minnow (Pimephales promelas) to atrazine increased the number of late stage oocytes, as well as reduced sperm maturation (Bringolf et al., 2004). These authors found decreases in egg production (fecundity), reduced fertilization rates, and reduced gonad-somatic index (GSI) in atrazine-exposed fish, but the reductions were not statistically significant. Endocrine-related effects, such as altered steroid hormones, have been observed in fish after environmental exposures to atrazine (Moore and Lower, 2001) and high exposures to atrazine (Spanò et al., 2004). Therefore, this study was designed to further understand the effects of atrazine on gonad function in fish during reproduction. The objective of this study was to evaluate the 
reproductive effects of graded, environmentally-relevant concentrations of atrazine on adult fathead minnow as measured through a series of biological endpoints.

\section{Materials and methods}

\subsection{Experimental design}

Fathead minnows were acclimated for a week prior to exposure to atrazine at 0 (solvent control, $0.02 \%$ acetone), $0.5,5.0$, and $50 \mu \mathrm{g} / \mathrm{L}$ in a flow-through diluter. Virgin, mature fathead minnow (purchased as embryos from Aquatic Bio Systems, Ft. Collins, CO and raised at CERC to 11-12 months old) were randomly assigned to a glass exposure tank $(6.5 \mathrm{~L})$ at a ratio of 2 females to 1 male, with a week to acclimate prior to exposure. Each tank contained one rectangular spawning substrate $(5.1 \mathrm{~cm}$ height, $8.9 \mathrm{~cm}$ width, and $8.9 \mathrm{~cm}$ length sections of glass). Breeding sets of fish were monitored over the course of the 1-week acclimation period and observed for signs of successful spawning behavior and egg production. Body weights were measured on a subset of the males $(2.8 \mathrm{~g} \pm 0.3 \mathrm{SE})$ and females $(1.8 \mathrm{~g} \pm 0.2 \mathrm{SE})$ on day 0 of exposure. Sampling of adults occurred at 14 and 30 days of exposure and was conducted from 19:00 to 24:00 to minimize effects of diurnal cycles of reproductive hormones. Spawning events (tanks containing eggs on a given day) and egg production were monitored in the morning, daily through 29 days of exposure. Eggs were collected from each tank, placed in a Petri dish with exposure water, held for $24 \mathrm{~h}$ in an incubator at $25 \pm 1^{\circ} \mathrm{C}$, then evaluated for viability and counted. In addition to checking spawning substrate, aquarium sides and siphoned waste were checked for eggs. Twelve replicate tanks per treatment were used, with six tanks sampled at each of the time points (14 and 30 days).

\subsection{Animal care and feeding}

Animals were held on a $16 \mathrm{~h}: 8 \mathrm{~h}$ (light:dark) photoperiod at $25 \pm 1{ }^{\circ} \mathrm{C}$ and fed brine shrimp (Artemia nauplii) twice daily. Tanks were siphoned clean $1 \mathrm{~h}$ after each feeding. Water quality was monitored weekly throughout the test and maintained within ASTM standards (ASTM, 2004) for oxygen (mean $7.5 \mathrm{mg} / \mathrm{L}$, range $5.5-8.3 \mathrm{mg} / \mathrm{L}$ ), $\mathrm{pH}$ (mean 8.4 , range $8.2-8.5$ ), hardness (mean $319 \mathrm{mg} \mathrm{CaCO}_{3} / \mathrm{L}$, range $298-336 \mathrm{mg} \mathrm{CaCO}_{3} / \mathrm{L}$ ), alkalinity (mean $242 \mathrm{mg} / \mathrm{L}$, range $226-256 \mathrm{mg} / \mathrm{L}$ ), and total ammonia (mean $0.13 \mathrm{mg} / \mathrm{L}$, range $0.04-0.44 \mathrm{mg} / \mathrm{L}$ ). Water flow was $11 \mathrm{~mL} / \mathrm{min}$ and turnover in the tanks was at a rate of 2.5 times/day.

\subsection{Atrazine exposure and water analysis}

Atrazine (98\% purity, Fluka Chemicals, Dorset, UK) was prepared in stock solutions of acetone:water (40:60\%) and stored in amber bottles at $4{ }^{\circ} \mathrm{C}$ prior to use in the diluter. Water concentrations of atrazine in the diluter and each exposure tank were checked twice weekly using enzyme-linked immunosorbant assay (ELISA) kits (Abraxis, Warminister, PA) in accordance with manufacturer's protocols. The method detection limit (MDL) for the atrazine ELISA procedure was $0.05 \mu \mathrm{g} / \mathrm{L}$ of water. Confirmatory analysis was performed on selected water samples by gas chromatography (Jimenez et al., 1997). Briefly, water samples were extracted using methylene chloride; the extract dried with sodium sulfate and filtered through glass fibers; volume reduced to $0.1 \mathrm{~mL}$ in methyl tertiary butyl ether; and triphenylphosphate (Chem Service Inc., $500 \mu \mathrm{g} / \mathrm{mL}$ in MtBE) was added as an instrumental internal standard. The extracts were analyzed by gas chromatographic nitrogen/phosphorus detector (GC/NPD) and quantified by PerkinElmers TotalChrom ${ }^{\mathrm{TM}}$ workstation chromatography data software. Samples for GC/NPD analysis were taken on three of the
8 days water was collected and each of those sample sets were comprised of triplicate water samples from each of the treatment groups $(0,0.5,5$, and $50 \mu \mathrm{g} / \mathrm{L})$. Quality control samples were analyzed with each sample set and included: atrazine-spiked water, matrix (tap) water blank, and a procedural blank. Additionally, atrazine stock concentrations used for the proportional diluter were also confirmed by GC/NPD.

\subsection{Fish collection, histological, and biochemical assays}

Adult fathead minnows were euthanized on collection days (14 and 30 days of exposure) with an overdose of unbuffered tricaine methanesulfonate (MS-222, Sigma, St. Louis, MO) and fish were weighed to the nearest $0.001 \mathrm{~g}$. Breeding tubercles were enumerated on males. Brains, livers, and gonads were dissected and preserved accordingly (see below) for each of the measured endpoints (histology, biochemistry, or gene expression). Gonads and brains were weighed to the nearest $0.0001 \mathrm{~g}$. Aromatase activity was measured in fresh samples of brain and ovary on a subset of female fish from each replicate and each treatment according to the methods of Orlando et al. (2002). 17 $\beta$-Estradiol and testosterone were measured in the eviscerated carcass of fathead minnow (Heppell and Sullivan, 2000).

\subsection{Histology}

Gonads of all fathead minnows were examined histologically to determine reproductive stage and to evaluate pathological lesions. One half of one lobe of the bi-lobed ovary and one entire lobe of the bi-lobed testis were preserved in Davidson's solution. Preparation of tissues followed standard histological techniques (Luna, 1968). Briefly, tissues were rinsed in two changes of $10 \mathrm{mM}$ HEPES buffer ( $\mathrm{pH}$ 7.4) and dehydrated by immersion in graded aqueous solutions ranging from $50 \%$ to $100 \%$ ethanol. This was followed by immersion in xylene and subsequent infiltration with paraffin. Tissue blocks were sectioned at $5 \mu \mathrm{m}$ thickness using a standard microtome, then mounted on glass slides and stored at room temperature until staining. In preparation for staining, the longitudinal, caudal sections were dewaxed with xylene and then rehydrated to water by immersion in graded aqueous solutions containing decreasing amounts of ethanol ranging from $100 \%$ to $0 \%$. Tissues were stained with Harris' hematoxylin and eosin for routine histological analysis under a compound microscope. Gonads were examined histologically to determine reproductive stages and evaluate pathological lesions.

Two sections of each ovary per fish were evaluated histologically at 0,14 , and 30 days to determine the presence of oogenesis stages including pre-vitellogenic (stage II), early vitellogenic (stage III; central germinal vesicle), mid-late vitellogenic (stage IV; germinal vesicle, GV, moving towards animal pole), and mature (stage V; GV beginning to breakdown). The number of oocytes in each section was counted, percentages calculated and an average determined for each ovary based on the two sections evaluated. Two sections of each testis per fish were also evaluated for stage of development and pathological lesions. Classification of testis developmental stages generally followed the description of Leino et al. (2005) as follows: tubules containing spermatogonia singly or in clusters (stage II); cysts of spermatocytes (stage III); mostly spermatids with some spermazoa in lumen (stage IV); and lumen expanded and filled with sperm (stage V). Mineralization in each testis was evaluated and the percentage of fish with this condition was noted in each treatment.

\subsection{Statistical analysis}

All of the statistical analyses were conducted using SAS statistical software (SAS ${ }^{\circledR}$, Cary NC) with the probability of a type I error 
set at $5 \%(p=0.05)$. Water concentrations of atrazine as determined by ELISA or GC were tested for significance by Student's $t$-test. Cumulative mean egg counts per tank were compared with general linear models (GLM) procedures of SAS and least square means contrasts. Mean egg production rates (eggs/tank with spawn/day or eggs/female/day) were compared using GLIMIX procedures of SAS with a poisson distribution. Weekly spawning rates (\# tanks with eggs/treatment/week) were compared using GLIMIX procedure with a logit distribution and the total numbers of spawns per treatment were compared using GLIMIX procedures and the likelihood of spawning with a binomial distribution. Contrasts of steroid concentrations, tubercles on males, aromatase activity in females, and GSI were conducted using GLM procedures, analysis of variance or co-variance, and least square means comparisons. Histological anomalies were compared by Kruskal-Wallace non-parametric analysis of ranks.

\section{Results}

\subsection{Exposure and adult mortality}

During the acclimation period, no anomalous behaviors were noted and spawning was observed in all of the treatment groups. Atrazine exposure concentrations remained relatively constant and near nominal concentrations for the entire course of the experiment (Table 1). Measured concentrations of atrazine were slightly lower than nominal concentrations. Mean $( \pm \mathrm{SE})$ measured concentrations of atrazine over the 30-day exposure were <MDL, $0.36( \pm 0.08), 4.76( \pm 1.0)$, and $47.9( \pm 4.7) \mu \mathrm{g} / \mathrm{L}$ in the control, low, medium, and high atrazine concentration groups, respectively (Table 1). Atrazine concentrations in the exposure water declined in all of the treatment groups on day 17 of exposure. The reason for the decline in water concentrations of atrazine on this day was not known; however water quality measurements for this period indicated that dissolved oxygen (5.57-6.99 $\mathrm{mg} / \mathrm{L}$ ) and ammonia (total ammonia $0.07-0.25 \mathrm{mg} / \mathrm{L}$ and estimated unionized ammonia $<30 \mu \mathrm{g} / \mathrm{L}$ ) remained within ASTM guidelines (ASTM, 2004). Water concentrations of atrazine were verified by GC-analysis (see Supplemental Information) and there were no significant differences $(p>0.05)$ within any of the treatments as compared to ELISA determinations. Metabolites of atrazine were not targeted for analysis due to the flow-through nature of the exposure systems. No significant mortality was observed in any of the treatment groups $(p>0.05)$. Mortality occurred in 10 (7\%) of the 144 breeding fathead minnows over the course of the egg production (three on day 6 , two on day 7 , one on day 9 , one on day 10 , one on day 12 , one on day 21 , and one on day 28 of exposure). Individuals were replaced (except the fish that died on day 21 and 28) to maintain the experimental design of the study. There were two tanks which were stocked with 2 males and one female (instead of the designed ratio of 1 male: 2 females). We discovered this when sampling; a control tank at 14 days, and one tank from the $0.5 \mu \mathrm{g} / \mathrm{L}$ exposures sampled at

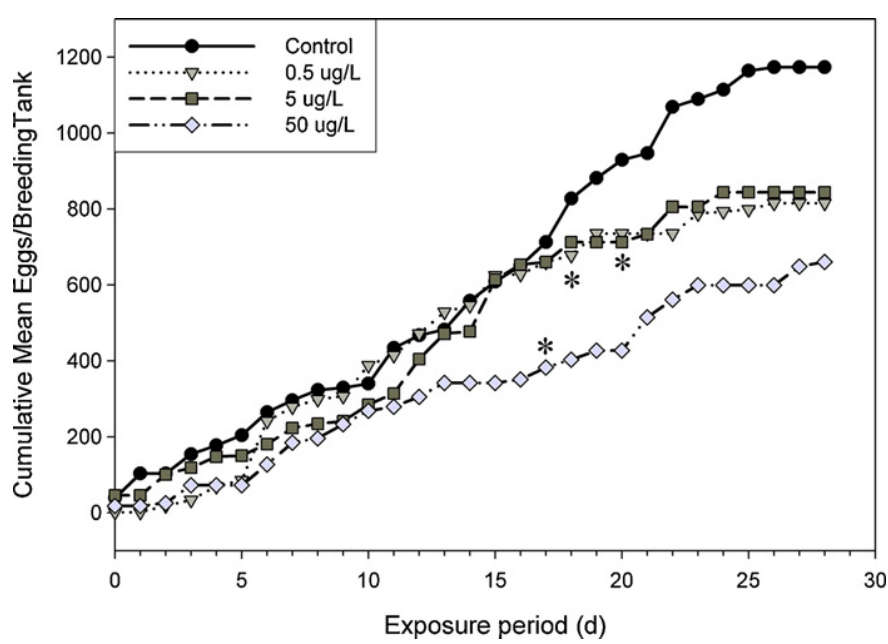

Fig. 1. Mean cumulative egg production (\#/tank) of fathead minnow exposed to atrazine. Cumulative egg counts were compared with SAS Statistical Software GLM procedure and least square means $(p=0.05)$. The first day in which cumulative egg numbers were different from controls is designated with an asterisk.

day 30 of exposure. These tanks were not included in subsequent data analysis for egg production.

\subsection{Egg production and spawning}

Cumulative mean egg production (cumulative mean number of eggs/tank) was reduced at all three exposure concentrations of atrazine (Fig. 1). Mean cumulative egg production was 1173,815 , 844 , and 661 eggs per breeding tank across the 0, 0.5, 5.0, and $50 \mu \mathrm{g} / \mathrm{L}$ treatment groups, respectively. Reductions in cumulative mean egg production rates were significant $(p \leq 0.05)$ by day 17 at $50 \mu \mathrm{g} / \mathrm{L}$ exposure, by day 18 at $0.5 \mu \mathrm{g} / \mathrm{L}$ exposure, and by day 20 at $5.0 \mu \mathrm{g} / \mathrm{L}$ nominal exposure concentration (Fig. 1). Cumulative egg production remained significantly reduced in atrazine treatment groups relative to the control group from these respective times until the end of the study. Cumulative total numbers of eggs produced per treatment over the course of the study were 9829 , 7351,7925 , and 6016 eggs in the $0,0.5,5.0$, and $50 \mu \mathrm{g} / \mathrm{L}$ exposures, respectively. This corresponds to reductions in the total number of eggs produced across a treatment of 25,19 , and $39 \%$ relative to the control, in the $0.5,5.0$, and $50 \mu \mathrm{g} / \mathrm{L}$ exposures, respectively, over the course of the study.

Egg production data were also evaluated on a subset of the entire experimental design. There were six tanks in which replacement fish were used due to mortality in one of the breeding adults prior to exposure day 12 . These tanks were removed from the data set and cumulative mean egg production was analyzed for the remaining tanks. Significant reductions in cumulative mean egg production were still observed at all of the treatment concentrations (see Figure S2 in Supplemental Information). The reductions

Table 1

Mean water concentrations $(\mu \mathrm{g} / \mathrm{L})$ of atrazine in fathead minnow exposure tanks.

\begin{tabular}{|c|c|c|c|c|c|c|c|c|c|}
\hline \multirow[t]{2}{*}{ Treatment $(\mu \mathrm{g} / \mathrm{L})$} & \multicolumn{9}{|c|}{ Exposure day } \\
\hline & Day 2 & Day 7 & Day10 & Day 14 & Day 17 & Day 21 & Day 24 & Day 28 & Mean $(\mathrm{SE})^{\mathrm{a}}$ \\
\hline 0 & $<\mathrm{MDL}^{\mathrm{b}}$ & $<\mathrm{MDL}$ & $<\mathrm{MDL}$ & $<\mathrm{MDL}$ & $<\mathrm{MDL}$ & $<\mathrm{MDL}$ & $<\mathrm{MDL}$ & $<\mathrm{MDL}$ & $<\mathrm{MDL}$ \\
\hline 0.5 & $0.05(0.04)$ & $0.35(0.13)$ & $0.49(0.09)$ & $0.52(0.04)$ & $<\mathrm{MDL}$ & $0.36(0.05)$ & $0.41(0.10)$ & $0.68(0.04)$ & $0.36(0.08)$ \\
\hline 5.0 & $4.91(0.82)$ & $1.89(0.24)$ & $2.67(0.48)$ & $8.28(0.70)$ & $0.76(0.14)$ & $7.69(0.53)$ & $7.71(0.52)$ & $4.27(0.19)$ & $4.76(1.0)$ \\
\hline 50 & $52.0(29.7)$ & $32.8(4.7)$ & $35.4(6.4)$ & $61.5(5.2)$ & $30.2(7.1)$ & $60.1(5.4)$ & $61.9(4.9)$ & $48.4(2.1)$ & $47.9(4.7)$ \\
\hline
\end{tabular}

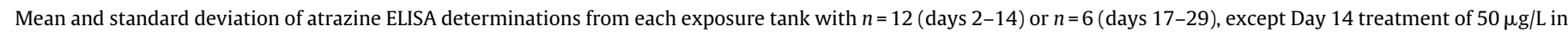
which one sample was lost, thus $n=11$ for that treatment.

a Treatment mean and standard error (SE) were determined across entire exposure period.

b Method detection limit (MDL) was $0.05 \mu \mathrm{g}$ atrazine/L for ELISA measurements. 


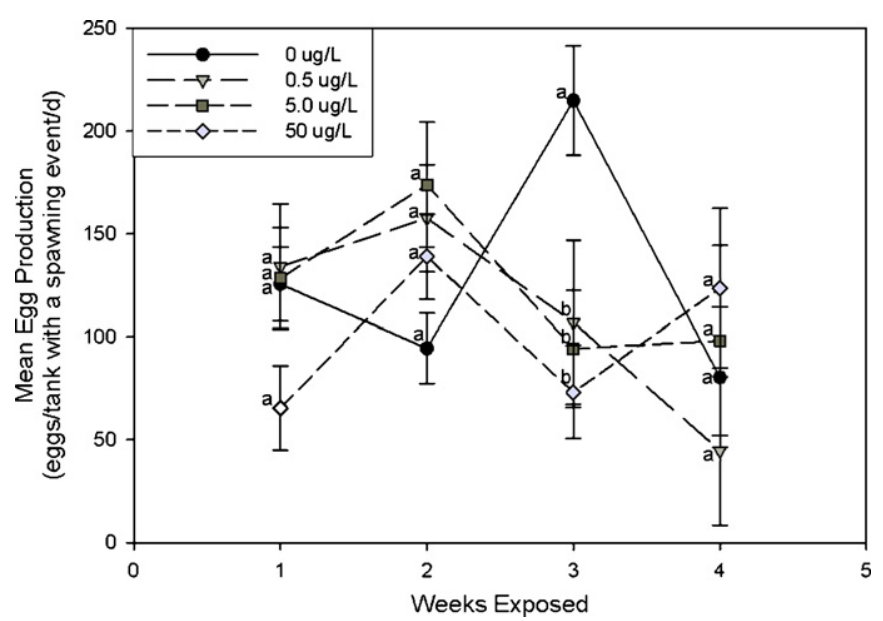

Fig. 2. Mean egg production (eggs/tank with a spawning event/day) of fathead minnow exposed to atrazine. Mean egg production was calculated as the mean of the daily number of eggs produced per tank with a spawning event over a given week. Statistical analysis of mean egg production rates was conducted with SAS Statistical Software using GLIMIX procedure with a poisson distribution and a critical value of $p=0.05$. Values with similar letters within a week are not different.

in cumulative mean egg production were first significant on exposure days 17,25 , and 19 in the $0.5,5.0$, and $50 \mu \mathrm{g} / \mathrm{L}$ treatments, respectively $(p \leq 0.05)$. Subsequent analyses were conducted with these tanks included to maintain the intended experimental design.

Weekly rates of egg production, normalized to the number of spawning sets of adults (tanks with eggs), were not significantly reduced with the exception of the third week of exposure (Fig. 2). During the third week of exposure to atrazine, there was a concentration-related decrease in the egg production rates; however, this relationship did not hold for the last week of the study (Fig. 2). Survival of the eggs for $24 \mathrm{~h}$ after collection was not affected by atrazine exposure relative to the control group (data not presented).

Atrazine exposure caused reductions in spawning events (days with eggs produced in a tank) which were statistically significant in some of the treatments during the latter half of the exposure (weeks 3 and 4) and were concentration-related after 3 weeks of exposure (Fig. 3). The decreases in spawning events resulted in an overall

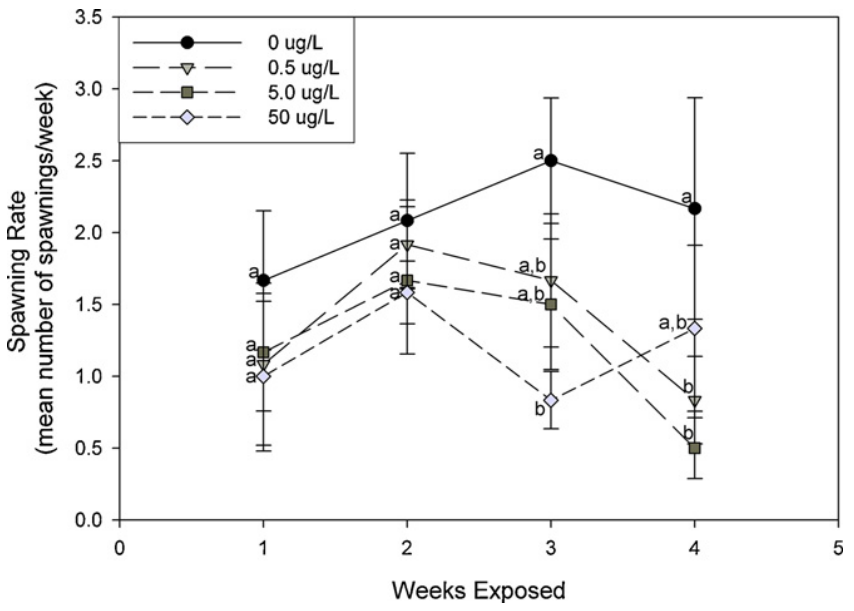

Fig. 3. Weekly spawning rates (mean number of spawnings/treatment) of fathead minnow exposed to atrazine. Mean number of tanks from a treatment which contained eggs on a given day for each week of exposure. Statistical analysis of weekly spawning rates was conducted with SAS Statistical Software using GLIMIX procedure with a logit distribution and a critical value of $p=0.05$. Values with similar letters within a week are not different.

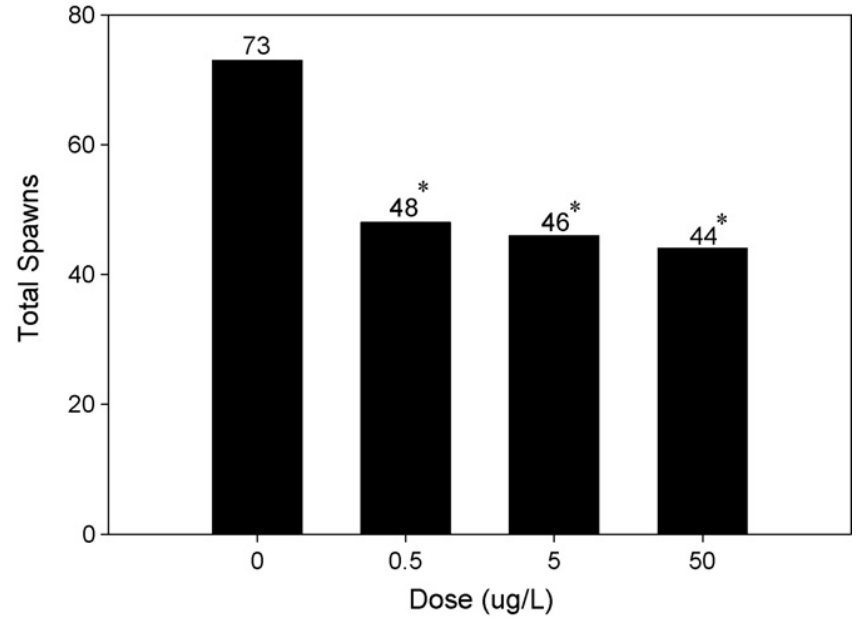

Fig. 4. Total number of spawning events in fathead minnow exposed to atrazine. Total number of tanks with spawned eggs observed during daily monitoring. Twelve replicate tanks per treatment were monitored through 14 days, then six replicate tanks per treatment were monitored until the end of the study. Statistical analysis of total number of spawns was conducted with SAS Statistical Software using GLIMIX procedure and the likelihood of spawning with a binomial distribution and a critical value of $p=0.05$. Values with an asterisk are different from controls.

concentration-related reduction in total spawning events over the course of the entire egg collection period (30 days) across all of the treatment groups (Fig. 4). However, the reductions in spawning events among the atrazine treatment groups were very similar and there appeared to be a threshold-type response for this effect.

\subsection{Steroids and aromatase activity}

No significant effects of atrazine were observed in steroid hormone concentrations in either gender or sampling time (Tables 2 and 3). There were decreases in testosterone of both males and females at 14 days, but these differences were not significant $(p>0.05)$ due to variation among individuals within the treatment groups. No significant differences in $\mathrm{E} / \mathrm{T}$ ratios were observed between control and treated fish at either collection time point (Tables 2 and 3). Gonad and brain aromatase activity (CYP19 isoforms) in female fathead minnow were not significantly different among atrazine treatments or controls at either 14 or 30 days of exposure (Table 3 ).

\subsection{Testicular staging}

Testicular stages (II-V) of developing sperm were observed in males sampled prior to the start of the exposures (day 0 , data not presented). A complete set of spermatic stages of developing sperm were also observed in control and high concentration $(50 \mu \mathrm{g} / \mathrm{L})$ males at day 14 , but no late stage testes (stage $\mathrm{V}$ ) were observed in males from the 0.5 and $5.0 \mu \mathrm{g} / \mathrm{L}$ concentration groups at this sampling time (Table 2). Stages III and IV were the modal stage among replicate fish across all concentrations and times, except males from the $50 \mu \mathrm{g} / \mathrm{L}$ exposure group on day 14; stage II was the modal stage among testes in this latter group (Table 2). The mean GSI values were not different among treatments (Table 2 ).

\subsection{Testicular pathologies}

Six types of pathological lesions were observed in testes of fathead minnows in this study. Granulomatous inflammations were found in one of six control males sampled on day 30 and one of six males from the $5 \mu \mathrm{g} / \mathrm{L}$ atrazine exposure sampled on day 
Table 2

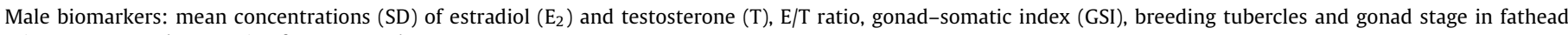
minnows exposed to atrazine for 14 or 30 days.

\begin{tabular}{|c|c|c|c|c|c|c|c|c|c|}
\hline & \multicolumn{9}{|c|}{ Concentration $(\mu \mathrm{g} / \mathrm{L})$} \\
\hline & Day & $n$ & Control & $n$ & 0.5 & $n$ & 5.0 & $n$ & 50 \\
\hline \multirow[t]{2}{*}{ Estradiol (ng/g) } & 14 & 6 & $0.7(0.7)$ & 6 & $0.5(0.6)$ & 6 & $1.0(0.1)$ & 5 & $0.4(0.6)$ \\
\hline & 30 & 5 & $0.8(0.4)$ & 5 & $0.2(0.7)$ & 5 & $0.7(0.5)$ & 6 & $0.7(0.4)$ \\
\hline \multirow[t]{2}{*}{ Testosterone (ng/g) } & 14 & 6 & $1.2(0.8)$ & 7 & $1.1(0.5)$ & 6 & $1.1(0.9)$ & 5 & $0.7(0.6)$ \\
\hline & 30 & 5 & $0.9(0.6)$ & 6 & $0.4(0.6)$ & 6 & $1.2(1.2)$ & 7 & $0.7(0.9)$ \\
\hline \multirow[t]{2}{*}{$\mathrm{E} / \mathrm{T}$ ratio } & 14 & 6 & $0.6(0.6)$ & 6 & $0.5(0.6)$ & 6 & $0.9(1.1)$ & 5 & $0.5(2.0)$ \\
\hline & 30 & 5 & $0.9(0.9)$ & 5 & $0.5(2.5)$ & 5 & $0.6(0.6)$ & 6 & $0.9(2.6)$ \\
\hline \multirow[t]{2}{*}{ GSI (\%) } & 14 & 6 & $1.1(1.1)$ & 6 & $1.2(0.4)$ & 7 & $1.4(0.2)$ & 6 & $1.4(0.4)$ \\
\hline & 30 & 6 & $0.9(0.8)$ & 6 & $1.0(0.4)$ & 6 & $1.8(2.6)$ & 7 & $1.4(0.7)$ \\
\hline \multirow[t]{2}{*}{ Breeding tubercles } & 14 & 5 & $23(5.2)$ & 6 & $21(4.3)$ & 6 & $27(4.4)$ & 6 & $25(5.3)$ \\
\hline & 30 & 5 & $25(5.9)$ & 3 & $18(7.8)$ & 3 & $25(6.1)$ & 3 & 18 (9.9) \\
\hline \multicolumn{10}{|l|}{ Testes staging } \\
\hline II & 14 & 6 & $1 / 6$ & 6 & $2 / 6$ & 6 & $1 / 6$ & 6 & $3 / 6$ \\
\hline III and IV & 14 & 6 & $3 / 6$ & 6 & $4 / 6$ & 6 & $5 / 6$ & 6 & $1 / 6$ \\
\hline V & 14 & 6 & $2 / 6$ & 6 & $0 / 6$ & 6 & $0 / 6$ & 6 & $2 / 6$ \\
\hline II & 30 & 6 & $1 / 6$ & 6 & $2 / 6$ & 5 & $0 / 5$ & 6 & $2 / 6$ \\
\hline III and IV & 30 & 6 & $3 / 6$ & 6 & $2 / 6$ & 5 & $3 / 5$ & 6 & $2 / 6$ \\
\hline V & 30 & 6 & $2 / 6$ & 6 & $2 / 6$ & 5 & $2 / 5$ & 6 & $2 / 6$ \\
\hline
\end{tabular}

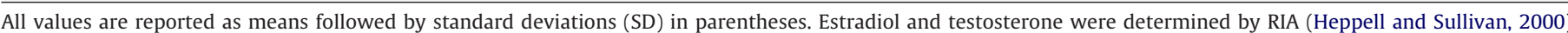

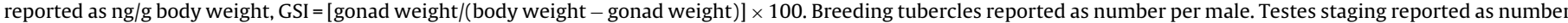
of individuals in a category per total individuals in a treatment combination. Number of individuals in each treatment combination is given ( $n$ ).

14. Mineralized material was observed in testicular tubules and efferent ducts at rates of $30,23,30$, and $17 \%$ in fish from $0,0.5$, 5.0 , and $50.0 \mu \mathrm{g} / \mathrm{L}$ treatment groups, respectively. A number of variably-sized perinucleolar stage oocytes (testicular oocytes) scattered among and within testicular tubules were observed in one of six males sampled on day 14 in the $5.0 \mu \mathrm{g} / \mathrm{L}$ atrazine exposure group (Fig. 5). We did not observe any follicle cells associated with these testicular oocytes. The same male also had granulomatous inflammation and mineralized material in the testes. Last, we observed a moderate frequency of germ cell syncytia (not shown) across all treatments and occasional pyknotic cells in males from the 5.0 and $50 \mu \mathrm{g} / \mathrm{L}$ concentration groups (not shown).

\subsection{Ovarian staging}

Pre-vitellogenic oocytes were predominant in ovaries prior to the beginning of the exposures (data not presented). By days 14 and 30 of the exposure period, ovaries were dominated by vitellogenic

Table 3

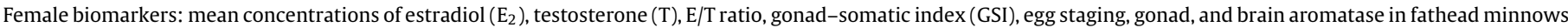
exposed to atrazine for 14 or 30 days.

\begin{tabular}{|c|c|c|c|c|c|c|c|c|c|}
\hline & \multicolumn{9}{|c|}{ Concentration $(\mu \mathrm{g} / \mathrm{L})$} \\
\hline & Day & $n$ & Control & $n$ & 0.5 & $n$ & 5.0 & $n$ & 50 \\
\hline \multirow[t]{2}{*}{ Estradiol (ng/g) } & 14 & 12 & $4.3(3.1)$ & 12 & $3.9(1.1)$ & 12 & $4.3(3.1)$ & 12 & $2.1(2.8)$ \\
\hline & 30 & 12 & $4.4(2.9)$ & 9 & $3.8(2.3)$ & 10 & $4.5(2.2)$ & 10 & $3.2(2.6)$ \\
\hline \multirow[t]{2}{*}{ Testosterone (ng/g) } & 14 & 11 & $0.8(0.4)$ & 12 & $0.7(0.5)$ & 12 & $0.5(0.4)$ & 10 & $0.3(0.4)$ \\
\hline & 30 & 12 & $0.6(0.4)$ & 9 & $0.4(0.5)$ & 10 & $0.7(0.4)$ & 10 & $0.6(0.8)$ \\
\hline \multirow[t]{2}{*}{$\mathrm{E} / \mathrm{T}$ ratio } & 14 & 11 & $5.4(5.9)$ & 12 & $5.7(4.6)$ & 12 & $8.5(2.9)$ & 10 & $6.6(5.7)$ \\
\hline & 30 & 12 & $7.5(5.0)$ & 9 & $8.7(10)$ & 10 & $6.9(17.4)$ & 10 & $5.1(3.2)$ \\
\hline \multirow[t]{2}{*}{ GSI (\%) } & 14 & 11 & $14(6)$ & 12 & $15(4)$ & 12 & $12(5)$ & 11 & $13(5)$ \\
\hline & 30 & 12 & $13(5)$ & 10 & $14(6)$ & 9 & $13(10)$ & 10 & $14(7)$ \\
\hline \multicolumn{10}{|l|}{ Egg staging } \\
\hline II (\%) & 14 & 8 & $34(6)$ & 10 & $40(10)$ & 11 & 35 (15) & 8 & $20(16)$ \\
\hline III and IV (\%) & 14 & 8 & $29(7)$ & 10 & $27(8)$ & 11 & $20(11)$ & 8 & $31(12)$ \\
\hline $\mathrm{V}(\%)$ & 14 & 8 & $35(9)$ & 10 & $30(8)$ & 11 & $36(17)$ & 8 & $40(12)$ \\
\hline II (\%) & 30 & 12 & $39(10)$ & 9 & $39(10)$ & 9 & 37 (17) & 8 & $33(13)$ \\
\hline III and IV (\%) & 30 & 12 & $26(7)$ & 9 & $16(6)$ & 9 & $23(12)$ & 8 & $24(14)$ \\
\hline V (\%) & 30 & 12 & $33(7)$ & 9 & $43(9)$ & 9 & $33(11)$ & 8 & $32(19)$ \\
\hline \multirow[t]{2}{*}{ Gonad aromatase (pmol/mg) } & 14 & 10 & $0.07(0.2)$ & 11 & $0.05(0.03)$ & 11 & $0.12(0.19)$ & 10 & $0.13(4.6)$ \\
\hline & 30 & 11 & $0.08(0.07)$ & 10 & $0.06(0.08)$ & 7 & $0.04(0.07)$ & 10 & $0.07(0.11)$ \\
\hline \multirow[t]{2}{*}{ Brain aromatase (pmol/mg) } & 14 & 6 & $0.01(0.0)$ & 6 & $0.01(0.0)$ & 6 & $0.01(0.0)$ & 5 & $0.01(0.01)$ \\
\hline & 30 & 6 & $0.03(0.01)$ & 6 & $0.03(0.03)$ & 5 & $0.03(0.01)$ & 5 & $0.03(0.01)$ \\
\hline
\end{tabular}

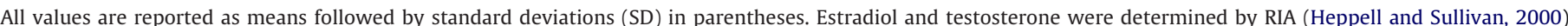

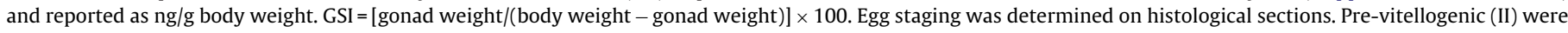

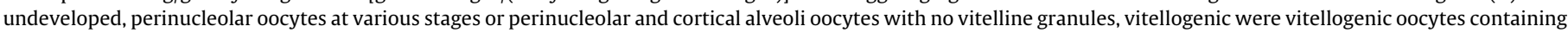

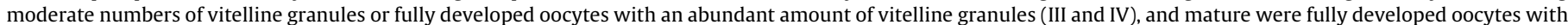

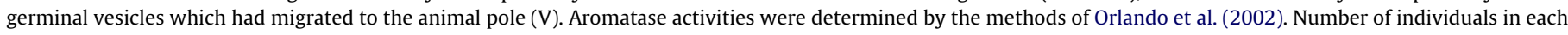
treatment is given $(n)$. 


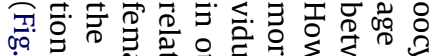

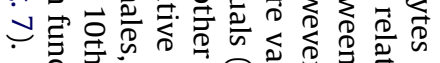

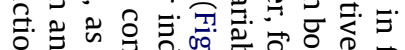

음

웅 8 을

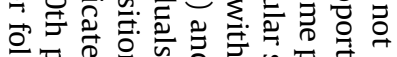

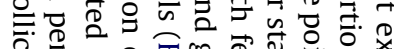

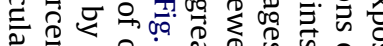

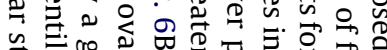

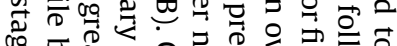

哈

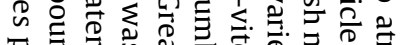

证

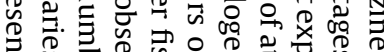

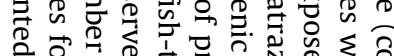

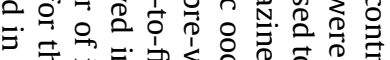

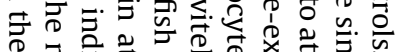

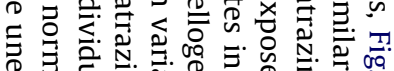

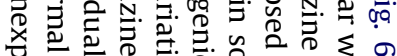

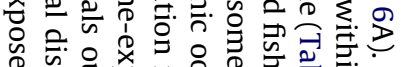

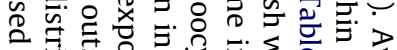

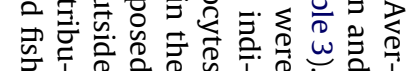

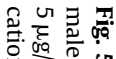

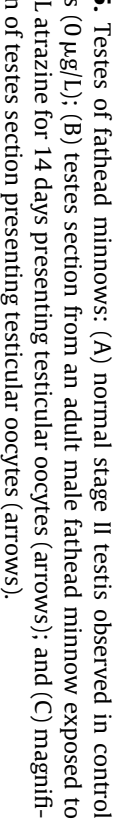

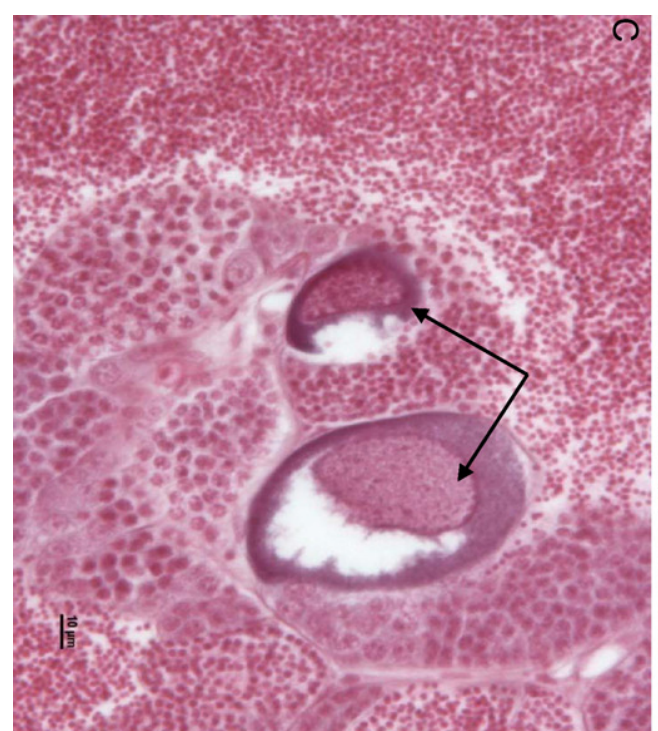

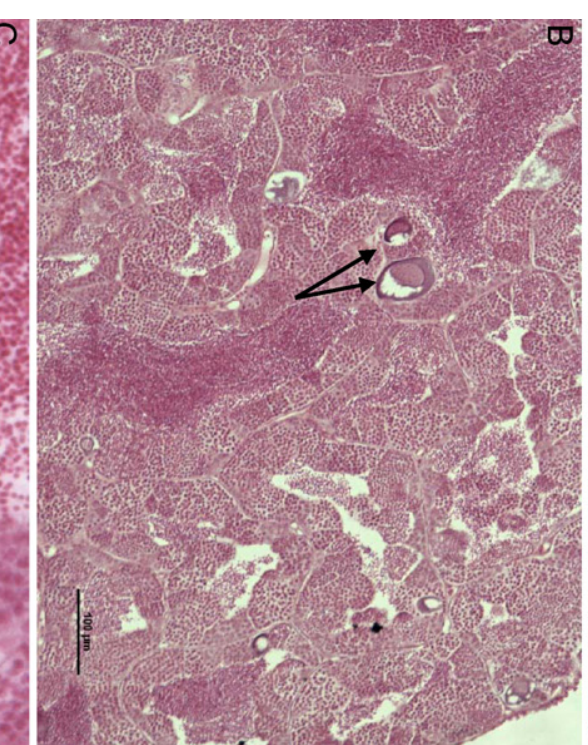

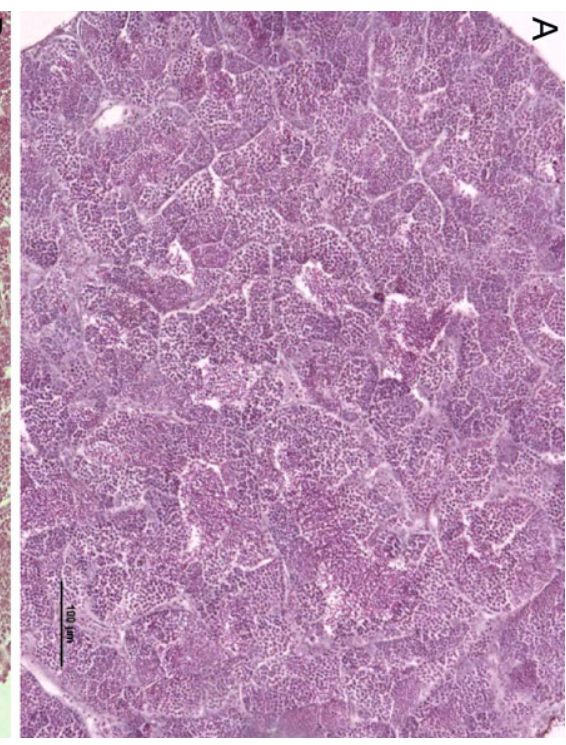

Table 4

Summary of male and female gonad abnormalities and corresponding rates of egg production, as a function of exposure concentrations of atrazine.

\begin{tabular}{|c|c|c|c|c|c|c|c|}
\hline \multirow{2}{*}{$\begin{array}{l}\text { Concentration } \\
\text { atrazine }(\mu \mathrm{g} / \mathrm{L})\end{array}$} & \multirow{2}{*}{$\begin{array}{l}N \text { (number } \\
\text { of tanks) }\end{array}$} & \multirow{2}{*}{$\begin{array}{l}\text { Percent }(\%) \text { tanks containing } \\
\text { no fish with abnormalities }\end{array}$} & \multirow{2}{*}{$\begin{array}{l}\text { Percent (\%) females without } \\
\text { abnormalities (by tank) }\end{array}$} & \multirow{2}{*}{$\begin{array}{l}\text { Percent (\%) females with } \\
\text { atretic follicles (by tank) }\end{array}$} & \multirow{2}{*}{$\begin{array}{l}\text { Percent (\%) females with lipid } \\
\text { accumulation in ovaries (by tank) }\end{array}$} & \multicolumn{2}{|l|}{ Total egg production } \\
\hline & & & & & & $\begin{array}{l}\text { Tanks with abnormalities } \\
\text { mean } \pm \text { SE (range) }\end{array}$ & $\begin{array}{l}\text { Tanks with no abnormalities } \\
\text { mean } \pm \text { SE (range) }\end{array}$ \\
\hline 0 & $10^{1}$ & 50 & 52 & 37 & 21 & $1002 \pm 304(244-1818)$ & $964 \pm 392(53-2102)$ \\
\hline 0.5 & 11 & 27 & 48 & 58 & 63 & $681 \pm 165(18-1725)$ & $526 \pm 96(356-688)$ \\
\hline 5 & 11 & 27 & 27 & 59 & 55 & $570 \pm 135(32-1320)$ & $930 \pm 221(695-1371)$ \\
\hline 50 & 12 & 25 & 25 & 62 & 46 & $402 \pm 99(0-970)$ & $799 \pm 341(204-1386)$ \\
\hline
\end{tabular}

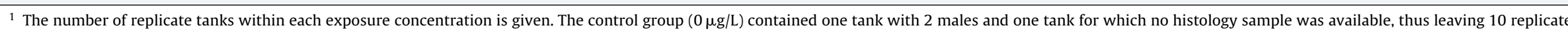

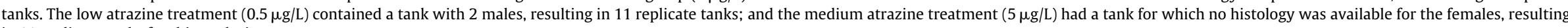
in 11 replicate tanks for this analysis. 

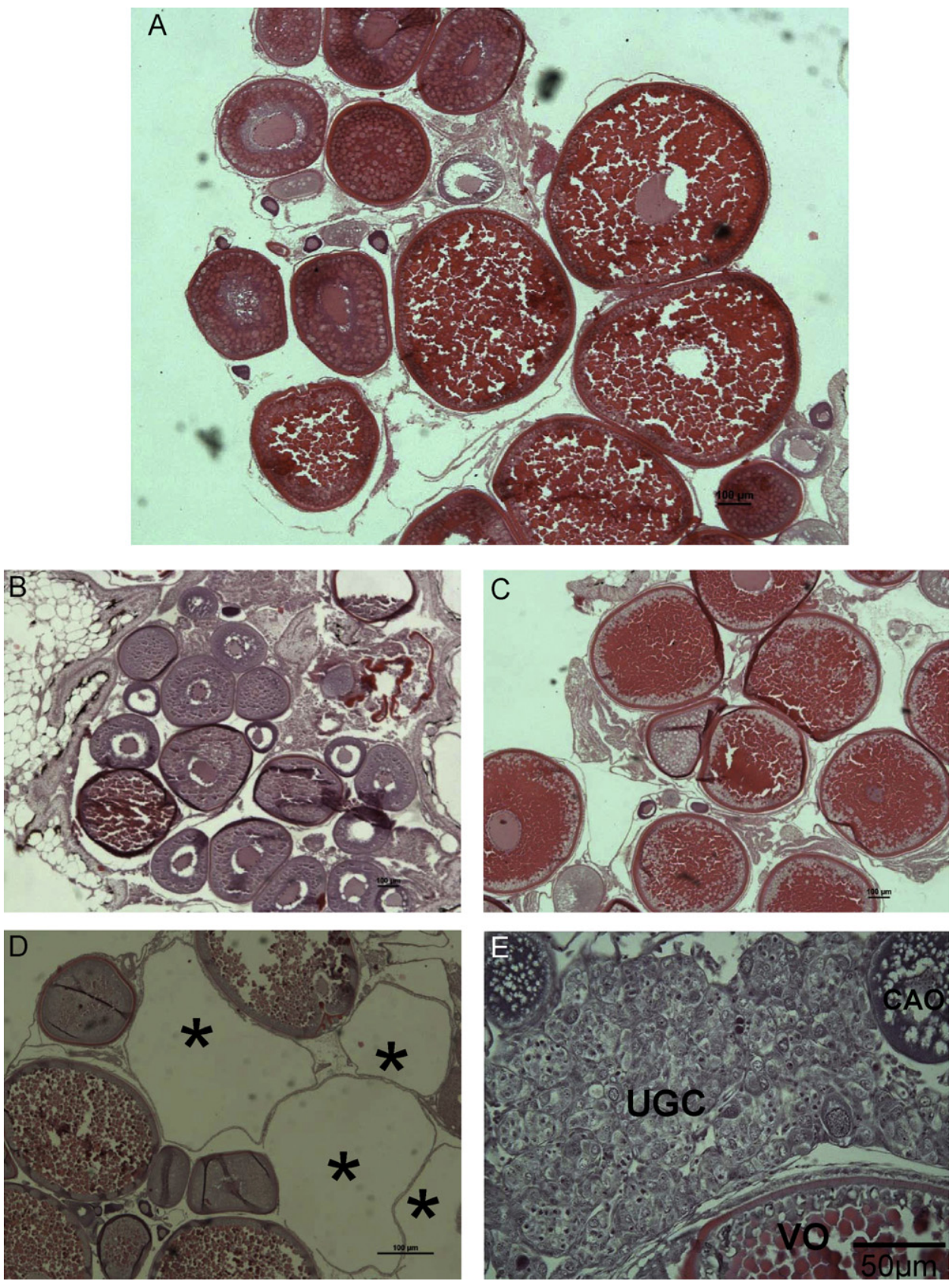

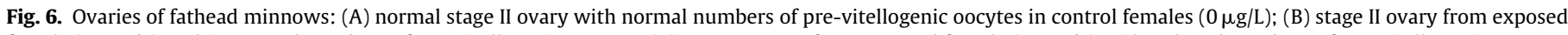

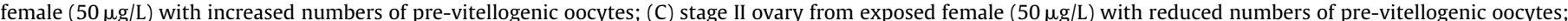

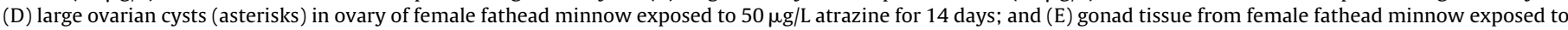
$5 \mu \mathrm{g} / \mathrm{L}$ atrazine for 14 days. Section shows the ovary to contain mostly undifferentiated germ cells (UGC), cortical alveoli oocytes (CAO), and a vitellogenic oocyte (VO).

\subsection{Ovarian pathologies}

Gonads from two fish (one from $5.0 \mu \mathrm{g} / \mathrm{L}$ and one from $50 \mu \mathrm{g} / \mathrm{L}$ groups) were filled with undifferentiated germinal cells and also contained a few scattered perinucleolar oocytes (micrograph not presented). Fish with these gonads were found in tanks with a normal female and normal male. A third fish, had both perinucleolar and vitellogenic oocytes scattered among undifferentiated germinal cells (Fig. 6E). This single fish with perinuclear and vitellogenic oocytes was found in the same tank as the single male with testicular oocytes and a normal female in the $5 \mu \mathrm{g} / \mathrm{L}$ treatment. A few additional pathological lesions were observed in the ovaries of atrazine-exposed fathead minnows. Pathologies in female gonads consisted of a trend of increased frequency of ovaries with lipid accumulation and atretic follicles in atrazine-exposed females (Table 4); however, there were no significant differences among the concentrations, likely due to small sample sizes. In addition, one individual exposed to $0.5 \mu \mathrm{g} / \mathrm{L}$ and three individuals exposed to $50 \mu \mathrm{g} / \mathrm{L}$ atrazine had multiple ovarian cysts that occupied a large portion of the ovary (Fig. 6D).

\section{Discussion}

Atrazine adversely affects neuroendocrine-regulated functions in vertebrates (Cooper et al., 2007), including fish (Spanò et al., 2004; Suzawa and Ingraham, 2008). The threshold concentrations of atrazine reported to cause endocrine-related effects in fish are $1-5 \mu \mathrm{g} / \mathrm{L}$ (Moore and Lower, 2001; Waring and Moore, 


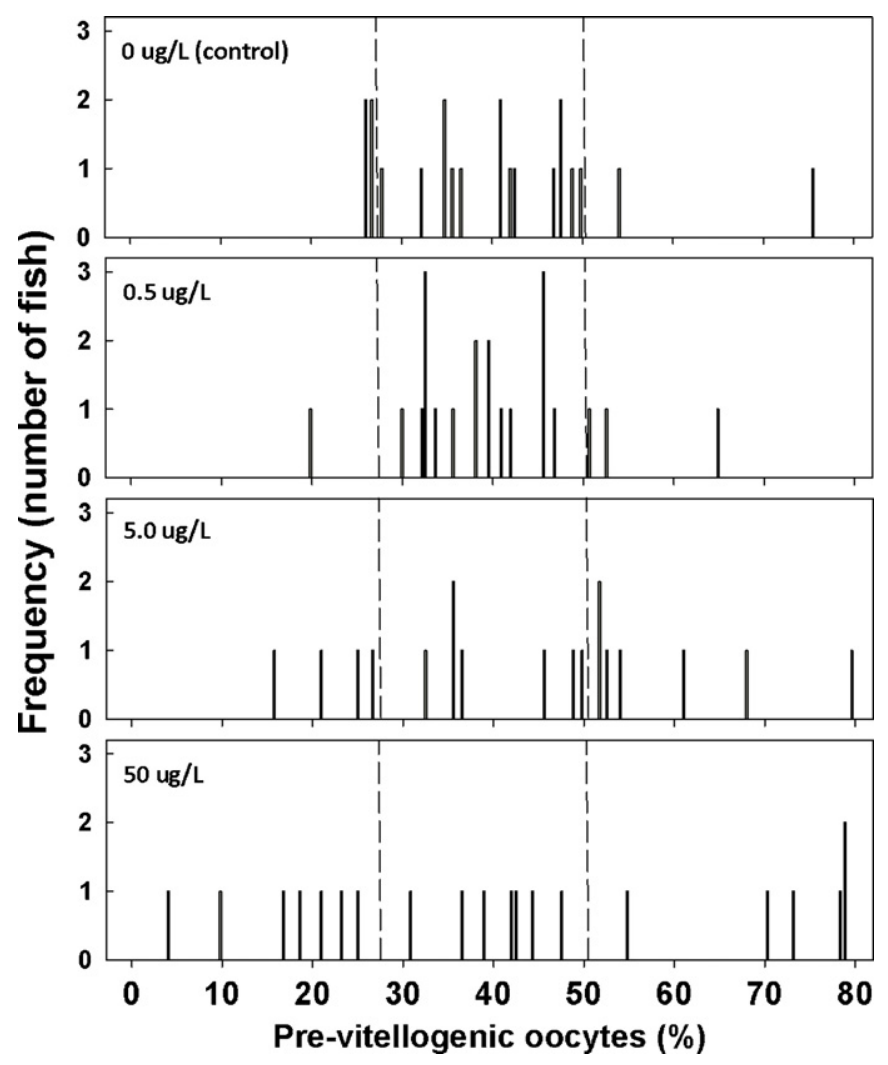

Fig. 7. Frequency distributions of pre-vitellogenic oocytes (PVO) in the ovaries of fathead minnows exposed to atrazine for 30 days. Individual females were categorized according to the percentage of PVO (\%) in their ovaries. The vertical dotted lines represent the 10th and 90th frequency percentiles of PVO for the control treatment group.

2004; Fortin et al., 2008; Suzawa and Ingraham, 2008) and these concentrations are commonly found in streams, rivers and lakes of agricultural regions in North America (Gilliom et al., 2006). Effective concentrations (lowest observable adverse effect concentrations, LOAEC) of atrazine have been reported to be $1.0 \mu \mathrm{g} / \mathrm{L}$ for olfactory-mediated endocrine functions in Atlantic salmon (Salmo salar) (Moore and Lower, 2001), $2.2 \mu \mathrm{g} / \mathrm{L}$ for up-regulation of brain aromatase activity in zebrafish (Danio rerio) (Suzawa and Ingraham, 2008), and $5 \mu \mathrm{g} / \mathrm{L}$ for osmotic control in mummichog (Fundulus heteroclitus) (Fortin et al., 2008). Effects of atrazine on reproductive function in fish have received little attention; yet common environmental concentrations of this herbicide are within these observed endocrine LOAEC values. Thus, testing of atrazine for population level metrics, such as fecundity, is needed to assess possible ecological risk of this herbicide.

\subsection{Comparison of atrazine-induced reductions in fecundity among studies}

Atrazine reduced egg production at all of our treatment concentrations $(0.5,5$, and $50 \mu \mathrm{g} / \mathrm{L})$ relative to the control group. Significant decreases in cumulative mean egg production of fathead minnow were observed at all concentrations of atrazine (Fig. 1). Cumulative numbers of eggs produced per female were reduced after nearly 2 weeks of exposure to the highest concentration of atrazine; although not significant $(p=0.05)$ until 17 days of exposure. The cumulative egg production rates in the low and medium atrazine treatment groups were nearly identical to the rate in the control group over the first 17 days of exposure and only began to deviate from the control group at that time. Significant reductions in cumulative egg production rates occurred after 18 and 20 days of exposure to 0.5 and $5 \mu \mathrm{g} / \mathrm{L}$ atrazine, respectively (Fig. 1). Decreases in cumulative egg production were not found to be statistically significant at similar exposure concentrations of atrazine in two previous studies with fathead minnow (Bringolf et al., 2004; Battelle Corporation, 2005). Our study conditions and protocols were similar in many ways to those described by Bringolf et al. (2004) and Battelle Corporation (2005); however, there were some key differences between the protocols of these studies which might have accounted for differences in our results and conclusions. First, in order to better simulate environmental exposure, our system was flow-through, as opposed to static-renewal (Bringolf et al., 2004). This undoubtedly led to differences in uptake kinetics and thus fish body burdens of atrazine between the studies. The exposure regime in the report by Battelle Corporation (2005) was flow-through, similar to our exposure system. Bringolf et al. (2004) observed nearly immediate reductions in cumulative egg production (fecundity presented in Fig. 1 of their paper). The fecundity curves for the atrazine-exposed groups were below those of the controls and slopes appeared to be deviating from the control group in their study, but the effects were not as dramatic as our study and not statistically significant (Bringolf et al., 2004). A similar trend was observed in the study conducted by Battelle Corporation (2005), with decreases in egg production; however, the concentration-related decreases observed in the atrazine treatments were not statistically significant. The Battelle Corporation (2005) report tested the power of the experimental design and suggested that the probability of detecting even a $20 \%$ difference in fecundity was low (22\%), based on the variability observed. Our protocol included greater numbers of replicate tanks per treatment (twelve tanks per replicate as opposed to four tanks per replicate) which provided greater statistical power. Our protocol also used a longer exposure (30 days) than the 21 day protocol Battelle Corporation (2005) and Bringolf et al. (2004) followed. Thus, part of the differences in the study conclusions may have been due to differences in the duration of exposure and differences in the power of the tests. Egg production rates in the control groups across our entire experiment (mean $=21.0 \pm 14.9 \mathrm{eggs} /$ female $/$ day $)$ were similar to that reported by the USEPA (mean $=20.5 \pm 14.3$ eggs/female/day) in their summary of fathead minnow reproductive assays (Wantanabe et al., 2007).

\subsection{Reduced spawning precedes decreases in fecundity}

The decrease we observed in cumulative egg production was largely due to reductions in spawning events as opposed to reduced egg production by each female (Figs. 3 and 4). Spawning events in all of the atrazine treatment groups were reduced in the first 2 weeks of exposure, but not statistically significant, and the reductions in spawning events became significant for the atrazine exposures during week three ( $50 \mu \mathrm{g} / \mathrm{L}$ treatment) or week four $(0.5$ and $5.0 \mu \mathrm{g} / \mathrm{L}$ treatments) of exposure. Bringolf et al. (2004) did not observe reductions in spawning in their study of atrazine effects on fathead minnow reproduction and spawning events were not reported in the study by Battelle Corporation (2005). A difference between the protocols of this study and the protocol used by Bringolf et al. (2004) was the numbers of fish used in each tank. We stocked one male and two females per tank, while Bringolf et al. (2004) stocked two males and four females per tank, as prescribed in the abbreviated 21-day fathead minnow reproductive assay developed by the USEPA (Ankley et al., 2001). We do not know if that difference may have been a factor in the reduced spawning events observed in our study. We observed concentration-dependent reductions in the total numbers of spawning events with increasing exposure concentrations of atrazine (Fig. 4); however, the degree of the reductions in spawning among atrazine exposure groups was 
small relative to the larger difference observed between control and any of the atrazine exposure groups. There appeared to be a threshold-type of response with this biological endpoint relative to atrazine exposure, as opposed to a graded, monotonic concentration-response. Reductions in spawning events could be due to either male-specific or female-specific effects on reproductive behavior. If there were male-specific effects of atrazine, our study with a single male per tank may allow those effects to be detected, while multiple males in a single tank might mask those effects. We did not measure breeding behavior in this study, so it is impossible to evaluate if such an effect was expressed. However, fathead minnow reproductive assays have been successfully used to monitor reproductive behavioral effects of chemicals (Ankley et al., 2001) and reproductive behaviors have been demonstrated to be sensitive measures of endocrine active agents (Zala and Penn, 2004). Last, direct effects on male reproductive behavior with secondary consequences on spawning cannot be ruled out. A male-specific effect would be consistent with the observations of atrazine-induced reductions in olfaction of male salmon (Salmo salar) to female priming pheromone (prostaglandin $\mathrm{F}_{2 \alpha}$ ) (Moore and Lower, 2001) and reduced sperm production in salmon (Moore and Waring, 1998). If males were not properly responding to the reproductive cues of female fathead minnows, a reduction in spawning events would be a natural outcome.

\subsection{Concentration-response relationships of atrazine-induced reproductive toxicity}

Concentration-related effects of atrazine on spawning events, egg production, and gonad anomalies in females were observed in this study. The concentration-response relationships of these endpoints were not always monotonic over the course of the study. Decreases in total egg production were greatest in the $50 \mu \mathrm{g} / \mathrm{L}$ exposure of atrazine and less in the $0.5 \mu \mathrm{g} / \mathrm{L}$ and the $5 \mu \mathrm{g} / \mathrm{L}$ treatment groups (Fig. 1); however, egg production in the low and medium treatments were indistinguishable from one another throughout the course of the study. Spawning events were decreased in a concentration-dependent manner when the entire experiment was considered (Fig. 4); however, as mentioned above, this response was more consistent with a threshold-type response. Weekly spawning rates were reduced in a concentrationdependent fashion on week three (Fig. 3). There appeared to be a marked threshold effect in the decreases in total numbers of spawning events, as opposed to a monotonic decrease across increasing atrazine concentrations (Fig. 4). Last, the decreases in the percentage of females without gonad anomalies followed a concentration-related pattern (Table 4). However, these responses (total egg production, spawning, and females with gonad abnormalities) were not monotonic throughout the course of the study. The reason for the lack of consistent and continuous monotonic concentration-response relationships over the course of the study cannot be discerned based on our experimental design. Clearly, non-monotonic dose-response curves are common in toxicology (Calabrese and Baldwin, 2003). Over the past decade, our knowledge and the importance of biphasic or hormetic responses of organisms to chemical stressors has increased (Calabrase, 2008). Hormesis is particularly apparent when reproductive toxicological endpoints are considered due to the significant role of the endocrine system in regulation of reproduction (Calabrase, 2008). The biochemical or physiological mechanisms leading to the atrazine-induced decreases in total egg production, spawning events, and normal ovarian cycling would be required to determine the reasons for the type of concentration-response relationships observed.

\subsection{Steroids and aromatase}

Atrazine can alter steroid hormone concentrations in peripheral blood of exposed fish. Spanò et al. (2004) observed concentrationrelated suppression of plasma androgens (11-ketotestosterone and testosterone) and induction of estrogen (17 $\beta$-estradiol) after 17 days of $1000 \mu \mathrm{g} / \mathrm{L}$ atrazine in goldfish (Carassius auratus). At more environmentally common surface water concentrations of atrazine ( 0.5 or $2 \mu \mathrm{g} / \mathrm{L}$ ), testosterone was significantly elevated, while 11 ketotestosterone lowered, but not significantly compared to the control male parr Atlantic salmon (Salmo salar, Moore and Lower, 2001 ). Steroid hormone concentrations, E/T ratios, and GSI values in our study were not significantly affected by atrazine at either sampling time point (Tables 2 and 3). Direct measurement of steroids in plasma may have been a more sensitive approach as opposed to the tissue method we used (Heppell and Sullivan, 2000). Additionally, aromatase activities in gonad and brain of females were not altered by atrazine. This is consistent with recent studies in female goldfish that reported no significant effects of atrazine on catalytic activity or expression of aromatase (Nadzialek et al., 2008). However, our findings are different than the results reported for female zebrafish where atrazine significantly induced aromatase expression (Suzawa and Ingraham, 2008). Suzawa and Ingraham (2008) concluded that atrazine was not a direct agonist for the estrogen receptor, but rather activated expression of aromatase through a complex mechanism involving NR5A receptor activation, as well as receptor phosphorylation, amplification of cAMP, and PI3K signaling. Whether this mechanism holds for fathead minnow, under chronic exposures to atrazine is unknown and beyond the scope of this paper.

\subsection{Gonad abnormalities reflective of reduced egg production}

Histological investigations indicated that abnormalities in the gonads could have contributed to the observed reduced egg production. Gonad lesions that reasonably could have resulted in reduced egg production were more prevalent in females from tanks receiving atrazine (Table 4 ). We observed more ovaries of atrazine-exposed minnows that contained atretic follicles as compared to control fish and only ovaries of atrazine-exposed minnows contained ovarian cysts. Bringolf et al. (2004) noted that atrazine exposure in fathead minnow led to greater variability in the maturation of ovaries. They attributed the increased variation in maturation to sensitive individuals within the population. Based on the increased variability we observed in ovarian development in atrazine-exposed fish, our data are consistent with their findings. Additionally, gonads comprised mainly of undifferentiated germ cells with few oocytes were present in fish from the $5 \mu \mathrm{g} / \mathrm{L}$ ( 2 fish) and $50 \mu \mathrm{g} / \mathrm{L}$ (1 fish) treatment groups. Presumably all three of these fish were genetic females based on the phenotypic markers of size, elevated E2 concentrations, and the lack of breeding tubercles. It may be possible that these fish were genetic males with testicular oocytes and we had simply misidentified them at stocking, but that does not seem to be likely. We do know that the fish in this study were well past the age of sexual differentiation (Uguz, 2008) leaving unexplained why the gonads of these three fish from the atrazine-exposed treatment groups were filled primarily with undifferentiated germ cells. We also observed ovarian cysts in a small number of atrazine-exposed females and none of the control females. Ovarian cysts have not previously been reported in atrazine-exposed fish, although such lesions were reported in other species exposed to atrazine. Multiple large ovarian cysts were present in fish from the 0.5 and $50 \mu \mathrm{g} / \mathrm{L}$ atrazine treatments. Polycystic ovaries in fish are not commonly reported in the scientific literature (J. Wolff pers. comm.). Nevertheless, pigs fed low amounts of atrazine developed multiple ovarian cysts and estrous 
was prolonged (Gojmerac, 1996). We observed a concentrationrelated increase (albeit not significant) in the number of tanks containing fish with atresia (Table 4). An increase in atresia was not observed in the study by Battelle Corporation (2005). These authors quantified the numbers of atretic follicles in individuals, while our observations were based on a more qualitative relative abundance (none/low/medium/high) of atretic follicles in female ovaries. We only observed a low degree of atresia in most of the females presenting this condition, which is consistent with the study by Battelle Corporation (2005). However, we observed a greater percentage of females in the atrazine treatment groups with this condition (Table 4). An increase in the proportion of oocytes undergoing atresia has been previously associated with atrazine exposure in goldfish (Spanò et al., 2004). Atretic oocytes can be found in both unstressed and stressed fish but are more prevalent in stressed fish and may indicate that the fish missed an opportunity to spawn (McCormick et al., 1989). We did not observe differences in mean GSI of females among treatments; however, the gonads of four putative females exposed to 5 and $50 \mu \mathrm{g} / \mathrm{L}$ atrazine for either 14 or 30 days were exceptionally small. The gonads of three of these individuals contained primarily undifferentiated germ cells with a few oocytes, similar to an asynchronously developing gonad; however, the observed oocytes were not solely located in one region. As indicated above, the fathead minnows used in the present study were well past the age of sexual differentiation ( 22 days postspawning in males; Uguz, 2008). Although the germinal epithelium was disorganized, the very small size of the gonad suggested it was not a germ cell neoplasm (Johnson et al., 2009).

Gonad abnormalities were also observed in atrazine-exposed male fathead minnows in this study, but it is not known if these lesions contributed to reductions in spawning. Testicular oocytes have not previously been reported in fish as a result of atrazine exposure and have rarely been reported for adult fathead minnow exposed to endocrine disruptors in general (Dietrich and Krieger, 2009). We identified one such intersex male that had been exposed to $5 \mu \mathrm{g}$ atrazine/L for 14 days. This was one male out of 48 males total used in our study. $P$. promelas is a differentiated gonochorist (ie. males and females are sexually distinct) and spontaneous occurrence of intersex is rare (Dietrich and Krieger, 2009). In fact, we did not find a report of a single intersex male among untreated animals upon review of the published toxicological literature for studies that used fathead minnow as the test organism and for which gonad histopathology was an endpoint. We do not know if the abnormal condition of the intersex male reduced its fertility as has been suggested for other fish species (Jobling et al., 2002). This fish was in a tank that contained a female with an abnormal, undifferentiated gonad (see above). Although the second female in this tank was normal, this set of fish only spawned a single clutch of 32 eggs in 14 days.

\subsection{Ovarian maturation disrupted by atrazine}

The follicular atresia and variability in the relative proportions of oocyte stages in the atrazine-exposed females could reflect a disruption in the normal processes of final maturation of oocytes with subsequent disturbances in ovulation and oviposition. The cause for this lack of release of oocytes may be due to direct action on the hypothalamic-pituitary-gonad axis in the female, as demonstrated with mammalian models of atrazine disruption of ovarian function (Cooper et al., 2000). Final maturation of fish oocytes is controlled in part by maturation-inducing steroids (MIS) which are stimulated by LH and act through a membrane progestin receptoralpha (mPR- $\alpha$ ), see Thomas et al. (2002) for review. The mPR- $\alpha$ activates nongenomic pathways and stimulates rapid physiological changes required for final maturation steps in oocyte development prior to ovulation (Thomas et al., 2002, 2006). Atrazine is effective at interfering with MIS binding to MPR and disrupting subsequent physiological responses in fish gonad development. Thomas and Doughty (2004) demonstrated that atrazine blocked the action of the progestin 17,20 $\beta, 21$-trihydroxy-4-pregnen-3-one to up-regulate sperm motility in Atlantic croaker (Micropogonias undulates). In the same model species, atrazine blocked final maturation of oocytes in vitro through this same membrane progestin receptor (Thomas and Sweatman, 2008). The MPR- $\alpha$ controls rapid, nongenomic responses in both female (oocyte maturation) and male (sperm hyperactivity) fishes (Thomas et al., 2002). Thus, atrazine interference with MIS-induced activation of mPR$\alpha$ has been a mechanism proposed for interference with both male and female reproductive processes. Atrazine-induced inhibition of mPR-related signaling was observed in Atlantic croaker at environmentally-relevant concentrations $(0.05 \mu \mathrm{M}$, Thomas and Doughty, 2004), similar to concentrations used in our study.

\section{Conclusions}

Environmentally-relevant concentrations of atrazine have significant effects on reproductive output in fathead minnow. The atrazine threshold concentration $(0.5 \mu \mathrm{g} / \mathrm{L})$ at which reductions were observed is lower than previously defined, yet well within surface water concentrations in agricultural areas. The observed reductions in egg production were largely due to reduced numbers of spawning events, which was not predicted by routine physiological measurements of endocrine disruption (steroid hormones, aromatase, or gonad-somatic indices). Evidence suggests that atrazine-induced reductions in egg production were attributable to effects on oocyte maturation processes; however, effects on males cannot be discounted. The effects on egg production and spawning in fathead minnow suggest the reproductive risks of atrazine exposure to feral fish populations in high use, agricultural areas may be under estimated by current evaluations.

\section{Disclaimer}

Any use of trade, product, or firm names is for descriptive purposes only and does not imply endorsement by the U.S. Government.

\section{Acknowledgements}

Support for this work was provided by the USGS Environmental Contaminants Biology Program. The authors thank James Candrl, Mandy Annis, Diane Nicks, James L. Zajicek and Rachel Claunch for their contributions to the conduct of this study; Robin Lipkin, Justin Buckler, and Vanessa Velez for assistance with data analysis, graphing, and publication; Dr. Mark Ellerseick, University of Missouri for statistical analysis; Dr. Wade Welshons, University of Missouri for estrogenic/anti-estrogenic activity screening of the fish food used prior to the study; Dr. Jeffrey Wolf, Experimental Pathology Laboratories, Sterling VA, for pathological analysis of gonad anomalies; and Dr. Gary Ankley, USEPA and Dr. Swee Teh, University of California-Davis for reviewing an earlier draft of this manuscript.

\section{Appendix A. Supplementary data}

Supplementary data associated with this article can be found, in the online version, at doi:10.1016/j.aquatox.2010.04.011.

\section{References}

American Society for Testing Materials (ASTM), 2004. Standard guide for conducting acute toxicity tests on test materials with fishes, macroinvertebrates, and amphibians (ASTM E729-96). ASTM Annual Book of Standards, vol. 11.05. ASTM West Conshohocken, PA. 
Ankley, G.T., Jensen, K.M., Kahl, M.D., Korte, J.J., Makynen, E.A., 2001. Description and evaluation of a short-term reproduction test with the fathead minnow (Pimephales promelas). Environ. Toxicol. Chem. 20, 1276-1290.

Battelle Corporation, 2005. Multi-chemical Evaluation of the Short-Term Reproduction Assay with the Fathead Minnow. Draft Final Report to U.S. Environmental Protection Agency, Columbus, OH, Contract No. 68-W-01-023 http://www.epa.gov/scipoly/oscpendo/docs/edmvac/draft fish repro multichemical.pdf.

Bringolf, R.B., Belden, J.B., Summerfelt, R.C., 2004. Effects of atrazine on fathead minnow in a short-term reproduction assay. Environ. Toxicol. Chem. 23, 1019-1025.

Calabrase, E.J., 2008. Hormesis: why it is important for toxicology and toxicologists. Environ. Toxicol. Chem. 27 (7), 1451-1474.

Calabrese, E.J., Baldwin, L.A., 2003. The hormetic dose-response model is more common than the threshold model in toxicology. Toxicol. Sci. 71, 246-250.

Cooper, R.L., Laws, S.C., Das, P.C., Narotsky, M.G., Goldman, J.M., Tyrey, E.L., Stoker, T.E., 2007. Atrazine and reproductive function: mode and mechanism studies. Birth Defects Res. B 80, 98-112.

Cooper, R.L., Stoker, T.E., Tyrey, L., Goldman, J.M., McElroy, W.K., 2000. Atrazine disrupts the hypothalamic control of pituitary-ovarian function. Toxicol. Sci. 53, 297-307.

Dietrich, D.R., Krieger, H.O., 2009. Histological Analysis of Endocrine Disruptive Effects in Small Laboratory Fish. John Wiley \& Sons, Hoboken, NJ.

Fortin, M.G., Couillard, C.M., Pellerin, J., Lebeuf, M., 2008. Effects of salinity on sublethal toxicity of atrazine to mummichog (Fundulus heteroclitus) larvae. Mar. Environ. Res. 65, 158-170.

Gidding, J.M., Anderson, T.A., Hall, L.W., Hosmer, A.J., Kendall, R.J., Richards, R.P., Solomon, K.R., Williams, W.M., 2005. Atrazine in North American Surface Waters: A Probablistic Aquatic Ecological Risk Assessment. Society of Environmental Toxicology and Chemistry, Pensacola, FL, p. 432.

Gilliom, R.J., Barbash, J.E., Crawford, C.G., Hamilton, P.A., Martin, J.D., Nakagaki, N., Nowell, L.H., Scott, J.C., Stackelberg, P.E., Thelin, G.P., Wolock, D.M., 2006. The Quality of Our Nation's Waters - Pesticides in the Nation's Streams and Ground Water, 1992-2001, vol. 1291. U.S. Geological Survey Circular, p. 172.

Gojmerac, T., 1996. Serum biochemical changes associated with cystic ovarian degeneration in pigs after atrazine treatment. Toxicol. Lett. 85, 9-15.

Heppell, S.A., Sullivan, C.V., 2000. Identification of gender and reproductive maturity in the absence of gonads: muscle tissue levels of sex steroids and vitellogenin in gat (Mycteroperca microlepis). Can. J. Fish. Aquat. Sci. 57, 148-159.

Jimenez, J.J., Bernal, J.L., del Nozal, M.J., Rivera, J.M., 1997. Determination of pesticide residues in water from small loughs by solid-phase extraction and combined use of gas chromatography with electron capture and nitrogen-phosphorous detection and high performance liquid chromatography with diode array detection. J. Chromatogr. A 778, 289-300.

Jobling, S., Coey, S., Whitmore, J.G., Kime, D.E., Van Look, K.J.W., McAllister, B.G., Beresford, N., Henshaw, A.C., Brighty, G., Tyler, C.R., Sumpter, J.P., 2002. Wild intersex roach (Rutilus rutilus) have reduced fertility. Biol. Reprod. 67, 515-524.

Johnson, R., Wolff, J., Braunbeck, T., 2009. OECD guidance document for the diagnosis of endocrine-related histopathology of fish gonads. Histopathology, 96.

Kettle, W.D., DeNoyelles Jr., F., Heacock, B.D., Kadoum, A.M., 1987. Diet and reproductive success of bluegill recovered from experimental ponds treated with atrazine. Bull. Environ. Contam. Toxicol. 8, 345-353.

Kiely, T., Donaldson, D., Grube, A., 2004. Pesticide Industry Sales And Usage - 2000 and 2001 Market Estimates. U.S. Environmental Protection Agency, Office of Prevention, Pesticides, and Toxic Substances, EPA-733-R-04-001, p. 33.
Leino, R.L., Jensen, K.M., Ankley, G., 2005. Gonadal histology and characteristic histopathology associated with endocrine disruption in the adult fathead minnow (Pimephales promelas). Environ. Toxicol. Pharm. 19, 85-98.

Luna, L.G., 1968. Manual of Histologic Staining Methods of the Armed Forces Institute of Pathology, third ed. McGraw-Hill, New York.

McCormick, J.H., Stokes, G.N., Hermanutz, R.O., 1989. Oocyte atresia and reproductive success in fathead minnows (Pimephales promelas) exposed to acidified hardwater environments. Arch. Environ. Contam. Toxicol. 18, 207214.

Moore, A., Lower, N., 2001. The impact of two pesticides on olfactory-mediated endocrine function in mature male Atlantic salmon (Salmo salar L.) parr. Comp. Biochem. Physiol. B 129, 269-276.

Moore, A., Waring, C.P., 1998. Mechanistic effects of a triazine pesticide on reproductive endocrine function in mature male Atlantic salmon (Salmo salar L.) parr. Pest. Biochem. Physiol. 62, 41-50.

Nadzialek, S., Spanò, L., Mandiki, S.N.M., Kestemont, P., 2008. High doses of atrazine do not disrupt activity and expression of aromatase in female gonads of juvenile goldfish (Carassius auratus L.). Ecotoxicology 17, 464-470.

Orlando, E.F., Davis, W.P., Guillette Jr., L.J., 2002. Aromatase activity in the ovary and brain of the eastern mosquito fish (Gambusia holbrooki) exposed to paper mill effluent. Envrion. Health Perspect. 110, 429-433.

Rosenfeld, H., Meiri, I., Elizue, A., 2007. Gonadotropic regulation of oocyte development. In: Babin, P.J., Cerdà, J., Lubzens (Eds.), The Fish Oocyte: From Basic Studies to Biotechnological Applications. Springer, The Netherlands, p. 508.

Spanò, L., Tyler, C.R., van Aerle, R., Devos, P., Mandiki, S.N., Silvestre, F., Thome, J.P., Kestemont, P., 2004. Effects of atrazine on sex steroid dynamics, plasma vitellogenin concentration and gonad development in adult goldfish (Carassius auratus L.). Aquat. Toxicol. 66, 369-379.

Suzawa, M., Ingraham, H.A., 2008. The herbicide atrazine activates endocrine gene networks via non-steroidal NR5A nuclear receptors in fish and mammalian cells. PLoS One 3, e2117, doi:10.1371/journal.pone.0002117.

Thomas, P., Doughty, K., 2004. Disruption of rapid, nongenomic steroid actions by environmental chemicals: interference with progestin stimulation of sperm motility in Atlantic croaker. Environ. Sci. Technol. 38, 6328-6332.

Thomas, P., Dressing, G., Pang, Y., Berg, H., Tubbs, C., Benninghoff, A., Doughty, K., 2006. Progestin, estrogen, and androgen G-protein coupled receptors in fish gonads. Steroids 71, 310-316.

Thomas, P., Sweatman, J., 2008. Interference by atrazine and bisphenol-A with progestin binding to the ovarian progestin membrane receptor and induction of oocyte maturation in Atlantic croaker. Mar. Environ. Res. 66, 1-2.

Thomas, P., Zhu, Y., Pace, M., 2002. Progestin membrane receptors involved in the meiotic maturation of teleost oocytes: a review and some new findings. Steroids 67, 511-517.

Uguz, C., 2008. Histological evaluation of gonadal differentiation in fathead minnows (Pimephales promelas). Tissue Cell 40, 299-306.

Wantanabe, K.H., Jensen, K.M., Orlando, E.F., Ankley, G.T., 2007. What is normal? A characterization of the values and variability in reproductive endpoints of the fathead minnow, Pimephales promelas. Comp. Biochem. Physiol. C 146, 348356.

Waring, C.P., Moore, A., 2004. The effect of atrazine on Atlantic salmon (Salmo salar) smolts in fresh water and after sea water transfer. Aquat. Toxicol. 66, 93104.

Zala, S.M., Penn, D.J., 2004. Abnormal behaviours induced by chemical pollution: a review of the evidence and new challenges. Anim. Behav. 68, 649-664. 